\title{
Simulation investigation of temperature distribution in large aluminium panel during autoclave age forming process
}

\author{
Yongqian $\mathrm{Xu}$, Central South University
}

\begin{abstract}
In the autoclave age forming process, temperature distribution in large aluminum panel is one of the most important factors affecting its final shape and performance. A 3D computational fluid dynamics (CFD) model for autoclave processing of a large aluminum panel with the dimension of $2500 \mathrm{~mm} \times 1300 \mathrm{~mm} \times 17 \mathrm{~mm}$ is developed and experimental evaluated. The results, expressed as root mean square error (RMSE), show that a good fitting between the experimental data and the calculated results is obtained. The magnitude of RMSE for panel, mold and fluid are $5.68,6.38$, and $11.03^{\circ} \mathrm{C}$, respectively. This confirmed that the proposed CFD model can be usefully applied for the prediction of panel's temperature distribution. Then, the temperature distribution in the studied panel during autoclave age forming process is investigated based on the numerical results. The slowest heating point (SHP) was positioned at the intermediate positions between 15 and $40 \%$ and between 55 and $70 \%$ of the panel length (about 30\% volume fraction of panel). Due to the thermal conduction between panel and mold, the time to reach the peak temperature difference of panel was delayed by $0.2 \mathrm{~h}$, though analyzing the temperature filed of panel can provide guidance for mold design and processing parameters optimization.
\end{abstract}

